\title{
Gene Mutation Analysis in EGFR Wild Type NSCLC Responsive to Erlotinib: Are There Features to Guide Patient Selection?
}

\section{Paola Ulivi ${ }^{1, *}$, Angelo Delmonte ${ }^{2}$, Elisa Chiadini ${ }^{1}$, Daniele Calistri ${ }^{1}$, Maximilian Papi ${ }^{3}$, Marita Mariotti ${ }^{2}$, Alberto Verlicchi ${ }^{4}$, Angela Ragazzini ${ }^{5}$, Laura Capelli ${ }^{1}$, Alessandro Gamboni ${ }^{6}$, Maurizio Puccetti ${ }^{7}$, Alessandra Dubini ${ }^{8}$, Marco Angelo Burgio ${ }^{2}$, Claudia Casanova ${ }^{4}$, Lucio Crinò ${ }^{9}$, Dino Amadori ${ }^{2}$ and Claudio Dazzi ${ }^{4}$}

1 Biosciences Laboratory, Istituto Scientifico Romagnolo per lo Studio e la Cura dei Tumori (IRST) IRCCS, Meldola 47014, Italy; E-Mails: elisa.chiadini@irst.emr.it (E.C.); daniele.calistri@irst.emr.it (D.C.); laura.capelli@irst.emr.it (L.C.)

2 Department of Medical Oncology, Istituto Scientifico Romagnolo per lo Studio e la Cura dei Tumori (IRST) IRCCS, Meldola 47014, Italy; E-Mails: angelo.delmonte@irst.emr.it (A.D.); marita.mariotti@irst.emr.it (M.M.); marco.burgio@irst.emr.it (M.A.B);dino.amadori@irst.emr.it (D.A.)

3 Department of Oncology, Per gli Infermi Hospital, Rimini 47900, Italy; E-Mail: maximilianpapi@libero.it

4 Department of Medical Oncology, Santa Maria delle Croci Hospital, Ravenna 48121, Italy; E-Mails: alberto28981@gmail.com (A.V.); c.casanova@ausl.ra.it (C.C.); c.dazzi@ausl.ra.it (C.D.)

5 Unit of Biostatistics and Clinical Trials, IRST IRCCS, Meldola 47014, Italy; E-Mail: angela.ragazzini@irst.emr.it

6 Oncology Unit, Degli Infermi Hospital, Faenza 48018, Italy; E-Mail: a.gamboni@ausl.ra.it

7 Pathology Unit, Santa Maria delle Croci Hospital, Ravenna 48121, Italy; E-Mail: m.puccetti@ausl.ra.it

8 Pathology Unit, Morgagni-Pierantoni Hospital, Forlì 47121, Italy; E-Mail: a.dubini@ausl.fo.it

9 Division of Medical Oncology, Santa Maria della Misericordia Hospital, Perugia 06156, Italy; E-Mail: lucio.crino@ospedale.perugia.it

* Author to whom correspondence should be addressed; E-Mail: paola.ulivi@irst.emr.it; Tel.: +39-543-739-277; Fax: +39-543-739-221.

Academic Editor: William Chi-shing Cho Received: 17 October 2014 / Accepted: 23 December 2014 / Published: 31 December 2014

Abstract: Tyrosine kinase inhibitors (TKIs) are very efficacious in non-small-cell lung cancer (NSCLC) patients harboring activating Epidermal Growth Factor Receptor (EGFR) 
mutations. However, about $10 \%$ of $E G F R$ wild type (wt) patients respond to TKI, with unknown molecular mechanisms of sensitivity. We considered a case series of 34 EGFR wt NSCLC patients responsive to erlotinib after at least one line of therapy. Responsive patients were matched with an equal number of non-responsive $E G F R$ wt patients. A panel of 26 genes, for a total of 214 somatic mutations, was analyzed by MassARRAY ${ }^{\circledR}$ System (Sequenom, San Diego, CA, USA). A 15\% KRAS mutation was observed in both groups, with a prevalence of $\mathrm{G} 12 \mathrm{C}$ in non-responders ( $80 \%$ vs. $40 \%$ in responders). NOTCH1, p53 and $E G F R$-resistance-related mutations were found more frequently in non-responders, whereas EGFR-sensitizing mutations and alterations in genes involved in proliferation pathways were more frequent in responders. In conclusion, our findings indicate that $p 53$, NOTCH1 and exon 20 EGFR mutations seem to be related to TKI resistance. KRAS mutations do not appear to influence the TKI response, although G12C mutation is more frequent in non-responders. Finally, the use of highly sensitive methodologies could lead to the identification of under-represented EGFR mutations potentially associated with TKI sensitivity.

Keywords: NSCLC; erlotinib; EGFR wt; $p 53 ; K R A S$

\section{Introduction}

Treatment with tyrosine kinase inhibitors (TKIs) has shown promising results in non-small-cell lung cancer (NSCLC) patients harboring activating epidermal growth factor receptor (EGFR) mutations. In view of the results reported by the IPASS study [1], gefitinib (IRESSA, AstraZeneca Pharmaceuticals, Wilmington, DE, USA) was the first TKI approved by the European Medicines Agency (EMEA) for first-line therapy in adults with locally advanced or metastatic EGFR mutated NSCLC. Moreover, the EURTAC study [2] led to the approval of erlotinib (TARCEVA Genentech, Inc., South San Francisco, CA, USA and OSI Pharmaceuticals, Inc., Melville, NY, USA) in the same patient setting. In unselected populations, erlotinib has shown activity in about $10 \%$ of patients in terms of response rate and progression-free survival (PFS) [3-5]. For this reason, it has already been approved for the treatment of locally advanced or metastatic NSCLC after the failure of at least one prior chemotherapy regimen, regardless of EGFR status. However, recent work by Garassino and colleagues [6] showed that, in a second-line setting, chemotherapy is more effective than erlotinib in terms of response rate and progression-free survival (PFS) in EGFR wild type (wt) NSCLC patients. Two recent meta-analyses focusing on the role of TKIs in EGFR wt patients confirmed the superiority of chemotherapy over TKIs in terms of PFS but not of overall survival (OS) [7,8]. However, in each of the studies reviewed there was a subgroup of EGFR wt patients who obtained a clinical benefit from TKI treatment, suggesting that factors other than EGFR mutation may lead to TKI sensitivity in a small number of patients. Other biological mechanisms may, in fact, be responsible for TKI sensitivity in EGFR wild type NSCLC patients, such as EGFR expression or phosphorylation, EGFR amplification, $E G F R$-ligand expression or the involvement of other biomarkers that play a role in the $E G F R$ pathway [9]. Moreover, highly sensitive methods for the evaluation of EGFR status can lead to 
the identification of activating mutations not highlighted by other conventional methodologies, justifying the response to TKIs [10].

In the present study we characterized NSCLC EGFR wt patients responding to erlotinib to identify potential biological markers of sensitivity and resistance to TKIs on the basis of their clinical features.

\section{Results}

In accordance with selection criteria, we identified 34 responsive patients among those treated with erlotinib in our institutions between January 2007 and June 2013. Median age was 69 years (range 44-88). Nineteen patients were male and 15 female. Twenty-five patients had adenocarcinoma (ADC), 6 had squamous cell carcinoma (SCC) and 3 had poorly differentiated carcinoma. Ten patients were current smokers, 8 former smokers and 8 non-smokers; smoking status was unknown for 8 patients. An equal number of non-responder patients, with similar characteristics for age, gender, smoking status and histotype, were analyzed. Patient characteristics are described in Table 1.

Table 1. Patient characteristics.

\begin{tabular}{|c|c|c|c|}
\hline Characteristics & Total No. & Responders & Non-Responders \\
\hline Overall Case Series & 68 & 34 & 34 \\
\hline \multicolumn{4}{|l|}{ Age, Years } \\
\hline$\leq 65$ & 27 & 13 & 14 \\
\hline$>65$ & 41 & 21 & 20 \\
\hline \multicolumn{4}{|l|}{ Gender } \\
\hline M & 38 & 19 & 19 \\
\hline $\mathrm{F}$ & 30 & 15 & 15 \\
\hline \multicolumn{4}{|l|}{ Smoking Habits } \\
\hline Smokers & 25 & 10 & 15 \\
\hline Former & 17 & 8 & 9 \\
\hline Never & 12 & 8 & 4 \\
\hline NA & 14 & 8 & 6 \\
\hline \multicolumn{4}{|l|}{ Histology } \\
\hline $\mathrm{ADC}$ & 52 & 25 & 27 \\
\hline $\mathrm{SCC}$ & 11 & 6 & 5 \\
\hline Others & 5 & 3 & 2 \\
\hline \multicolumn{4}{|l|}{ Lines of Therapy } \\
\hline II & 48 & 26 & 22 \\
\hline III & 16 & 6 & 10 \\
\hline IV & 4 & 2 & 2 \\
\hline \multicolumn{4}{|l|}{ ECOG PS } \\
\hline $0-1$ & 58 & 32 & 26 \\
\hline 2 & 6 & 1 & 5 \\
\hline n.a. & 4 & 1 & 3 \\
\hline
\end{tabular}

ADC, adenocarcinoma; SCC, squamous cell carcinoma; ECOG PS, Eastern Cooperative Oncology Group Performance Status; n.a., not available. 
Overall, we found that $18(53 \%)$ responsive and $16(47 \%)$ non-responsive patients had a gene mutation highlighted by MassARRAY ${ }^{\circledR}$ System. The different gene mutations found in the two groups are represented in Table 2. No significant correlations between mutations and clinical features were identified. However, in the responder group 10 patients with a mutation were former or never smokers (56\%), 3 were smokers (17\%) and 5 were unknown (28\%). In the control arm, 5 patients were former or never smokers $(31 \%), 8$ were smokers $(50 \%)$ and 3 were unknown $(19 \%)$.

Table 2. Gene mutations identified using LungCarta kit.

\begin{tabular}{cccc}
\hline Gene Mutation & Total No. (\%) & No. of Responders (\%) & No. of Non-Responders (\%) \\
\hline EGFR (sensitivity) & $2(3 \%)$ & $2(6 \%)$ & - \\
$E G F R$ (resistance) & $2(3 \%)$ & - & $2(6 \%)$ \\
KRAS & $10(15 \%)$ & $5(15 \%)$ & $5(15 \%)$ \\
PIK3CA & $3(4 \%)$ & $3(9 \%)$ & - \\
BRAF & $2(3 \%)$ & $2(6 \%)$ & - \\
$p 53$ & $6(9 \%)$ & $1(3 \%)$ & - \\
STK11 & $2(3 \%)$ & $2(6 \%)$ & - \\
NTRK2 & $1(1 \%)$ & $1(3 \%)$ & $3{ }^{\S}(8 \%)$ \\
NOTCH1 & $4(6 \%)$ & $1(3 \%)$ & $1(3 \%)$ \\
$E P H A 5$ & $2(3 \%)$ & $1(3 \%)$ & $1(3 \%)$ \\
$A K T$ & $1(1 \%)$ & - & - \\
$M E T$ & $1(1 \%)$ & $1 *(3 \%)$ & - \\
\hline
\end{tabular}

* This patient also had an EGFR L858R mutation; ${ }^{\S}$ One of these patients also had a p53 G245C mutation.

Among responders, the analysis performed by MassARRAY ${ }^{\circledR}$ System identified 2 patients with sensitizing EGFR mutations, one exon 19 deletion and one point mutation in exon 21 (L858R), previously missed by Pyrosequencing. The patient with the L858R mutation showed a concomitant mutation in MET (N375S). No EGFR sensitizing mutations were seen in non-responders, but 2 showed EGFR exon 20 mutations (P753S and L747S).

Mutation of $K R A S$ gene was observed in 5 responders (15\%) and in 5 non-responders (15\%). In the former group, 2 patients had G12C mutation of KRAS (40\%), one G12V (20\%), one G12D (20\%) and one G13D (20\%). Among non-responders, 4 had G12C KRAS mutations (80\%) and one G12V mutations (20\%). All KRAS mutated tumors were adenocarcinoma (ADC).

Mutation of p53 (R248Q) was identified in one responder with ADC, and in 5 non-responders (G245C, R273L, R249S, Y220C, R158C), 2 of these in a squamous cell carcinoma (SCC), 2 in ADC and one in large cell carcinoma. A higher $p 53$ mutation rate (15\%) was observed in the non-responder patients as compared to responders $(3 \%),(p=0.09)$. All $p 53$ mutated non-responsive patients were smokers, whereas the $p 53$ mutated responsive patient had never been a smoker.

Mutation R2328W of the NOTCH1 gene was present in one responsive SCC patient and in 3 non-responders (1 SCC and $2 \mathrm{ADC}$ ). Mutation S566Y of EPHA5 was found in one responsive and one non-responsive patient, both with ADC. In the non-responder group, one patient with ADC showed an E17K mutation in the $A K T$ gene. In the responsive group, 9 mutations (26\%) were found in genes concerning proliferation pathways: PIK3CA (2 ADC with exon 9 E545K, and a poorly differentiated carcinoma with H1047R), BRAF (V600E in 2 ADC), STK11 (V197fs 69 in one ADC and F354L in 
one SCC), NTRK2 (L755L in a SCC) and MET (N375S). None of these mutations were identified in the control arm $(p=0.005)$.

No relevant correlations were found between different types of mutations and duration of response in the experimental group. Among mutated responsive patients, all but one had a stable disease and the median duration of response was 8 (range 6-10), 13.2 (range 7-22), 15 (range 9-20) and 11 (range 6-13) months for patients with mutations in $E G F R, K R A S, P I K 3 C A$ and $B R A F$, respectively. One patient with a PIK3CA mutation showed partial response lasting for 20 months. Patients with mutation of NTRK2, EPHA5, p53 and NOTCH1 showed stable disease as a best response lasting for 6, 17, 19 and 10 months respectively (Table 3 ). Among responsive wt patients, 5 showed a partial response with a median duration of 10 months (range 7-12 months) while the others had stable disease as a best response with a median response duration of 9.5 months (range 6-14 months).

Table 3. Clinical-pathological characteristics and type of response in mutated responder patients.

\begin{tabular}{|c|c|c|c|c|c|}
\hline Gene Mutations & Age & Gender & Smoking Habits & Histotype & Type and Duration of Response (Months) \\
\hline \multicolumn{6}{|l|}{ EGFR sensitivity } \\
\hline Del 19 & 76 & M & No & PDC & $\mathrm{SD}(6)$ \\
\hline $\mathrm{L} 858 \mathrm{R} *$ & 77 & $\mathrm{~F}$ & No & $\mathrm{ADC}$ & $\mathrm{SD}(10)$ \\
\hline \multicolumn{6}{|l|}{ KRAS } \\
\hline $\mathrm{G} 12 \mathrm{~V}$ & 64 & M & Ex & $\mathrm{ADC}$ & $\mathrm{SD}(7)$ \\
\hline $\mathrm{G} 12 \mathrm{C}$ & 71 & M & Yes & $\mathrm{ADC}$ & $\mathrm{SD}(13)$ \\
\hline $\mathrm{G} 12 \mathrm{C}$ & 75 & M & n.a. & $\mathrm{ADC}$ & $\mathrm{SD}(15)$ \\
\hline G12D & 77 & $\mathrm{~F}$ & No & $\mathrm{ADC}$ & $\mathrm{SD}(9)$ \\
\hline G13D & 62 & $\mathrm{M}$ & Yes & $\mathrm{ADC}$ & SD (22) \\
\hline \multicolumn{6}{|l|}{ PIK3CA } \\
\hline E545K & 77 & M & Ex & $\mathrm{ADC}$ & SD (9) \\
\hline E545K & 71 & M & n.a. & $\mathrm{ADC}$ & SD (16) \\
\hline $\mathrm{H} 1047 \mathrm{R}$ & 79 & $\mathrm{~F}$ & No & PDC & PR (20) \\
\hline \multicolumn{6}{|l|}{$B R A F$} \\
\hline V600E & 69 & M & Yes & $\mathrm{ADC}$ & SD (16) \\
\hline V600E & 67 & $\mathrm{~F}$ & n.a. & $\mathrm{ADC}$ & $\mathrm{SD}(6)$ \\
\hline \multicolumn{6}{|l|}{ STK11 } \\
\hline V197fs69 & 47 & M & n.a. & $\mathrm{ADC}$ & $\mathrm{SD}(8)$ \\
\hline F354L & 75 & $\mathrm{M}$ & Ex & $\mathrm{SCC}$ & $\mathrm{SD}(8)$ \\
\hline \multicolumn{6}{|l|}{ NTRK2 } \\
\hline $\mathrm{L} 755 \mathrm{~L}$ & 64 & $\mathrm{~F}$ & No & $\mathrm{SCC}$ & $\mathrm{SD}(6)$ \\
\hline \multicolumn{6}{|l|}{ EPHA5 } \\
\hline S566Y & 50 & $\mathrm{~F}$ & n.a. & $\mathrm{ADC}$ & SD (17) \\
\hline \multicolumn{6}{|l|}{$p 53$} \\
\hline R248Q & 55 & $\mathrm{~F}$ & No & $\mathrm{ADC}$ & SD (19) \\
\hline \multicolumn{6}{|l|}{ NOTCH1 } \\
\hline $\mathrm{R} 2328 \mathrm{~W}$ & 66 & $\mathrm{M}$ & Ex & $\mathrm{SCC}$ & SD (10) \\
\hline
\end{tabular}

* This patient also had a N375S MET mutation. PDC, poorly differentiated carcinoma; SD, stable disease; ADC, adenocarcinoma; SCC, squamous cell carcinoma; PR, partial response; n.a., not available; Ex, former smoker. 


\section{Discussion}

EGFR-TKIs are a new class of drugs that have shown strong activity in NSCLC patients. Although the most significant results have been seen in EGFR mutated NSCLC, approximately $10 \%$ of $E G F R$ wt patients may have an improvement in terms of response rate and progression-free survival [3-5]. At present, no clinical or biological parameters have been defined to identify patients with greater chances of response.

In our study, we performed a molecular characterization of EGFR wt NSCLC patients responsive to erlotinib in order to define markers predictive of response. KRAS mutation rate was equal in responders and non-responders (15\% in the overall population of both groups, $20 \%$ in ADC). This result, even if obtained in a small number of cases, seems to confirm the data present in the literature according to which KRAS mutation is not predictive of non-response to TKIs. However, inconsistent data on the role of $K R A S$ mutations in relation to TKI response are reported in the literature. Several authors found that KRAS mutated patients did not have a significant response benefit from TKI treatment, in different lines of therapy [11-14]. Conversely, several trials showed that no difference in terms of TKI response was identified based on $K R A S$ status $[15,16]$. Other studies have analyzed the role of KRAS mutation subtype in relation to TKI response. A study by Metro et al. [17] showed that patients with $K R A S$ codon 13 mutation showed a worse PFS and OS in comparison to patients with codon $12 K R A S$ mutations, although data were obtained in a small case series. Another study, conducted on a larger case series, showed that the G12C KRAS mutation is a negative predictor of efficacy of TKIs, in comparison to the other KRAS mutations [18]. According to the latter data, our case series showed that the $\mathrm{G} 12 \mathrm{C}$ mutation was more frequently found in non-responders $(80 \%)$ in comparison to responders (40\%), suggesting that the G12C mutation may have a more specific value in predicting response to TKI.

In the responder group, $26 \%$ of mutations involved PIK3CA (9\%), BRAF (6\%), STK11 (6\%), NTRK2 (3\%) and MET (3\%) genes were found, and these were not found in the non-responder group. All but one patient with these mutations had stable disease for a median time of approximately 10 months (range 6-16). One patient with a PIK3CA mutation showed a partial response for 20 months. Despite confirmation in several works that PIK3CA, BRAF and MET mutations can be major causes of acquired resistance to TKIs [19,20], limited data are available regarding their role at the baseline, prior to the start of any kind of treatment, and lack of information is probably due to their low incidence [21,22]. So far, given that all of the histological specimens used for analysis in our study have been collected at the baseline, our data suggest that these mutations may have a predictive role in patient selection that must be investigated in further prospective studies.

In the non-responder group, $29 \%$ of patients showed exon 20 EGFR mutations, p53 or NOTCH1 alterations, which are associated in the literature with TKI resistance [23-25]. In particular we found a percentage of $p 53$ gene mutations higher than that in responders $(15 \%$ vs. 3\%, respectively; $p=0.09)$ without a statistically significant value, probably due to the low number of cases. A recent study showed that non-disruptive mutations of the $p 53$ gene is an independent factor of shorter survival in advanced NSCLC with a possible predictive negative value of response to TKIs [23]. Moreover, a previous in vitro study demonstrated the central role of $p 53$ in the development of acquired resistance to EGFR inhibitors [24]. 
In the responder group, however, alterations of $p 53$ and $\mathrm{NOTCH1}$ were present in $5.9 \%$ of patients. The best response to erlotinib in these cases was stable disease with a median duration of 13.6 months (range 7-22 months). Prospective evaluations are needed to clarify whether the presence of these mutations before the start of cancer treatment could represent a potential criterion for patient selection. Moreover, taking into account the fact that we only evaluated hot spot $p 53$ mutations in our study, it might be interesting to extend our analysis to other gene alterations.

Finally, our data showed that by using a more sensitive method than Pyrosequencing, for example the MassARRAY ${ }^{\circledR}$ System, it is possible to identify a higher number $(6 \%)$ of EGFR mutated patients. These results are in line with a previous study, performed in an Asian case series, showing an increase of approximately $20 \%$ of EGFR mutation using Peptide Nucleic Acid (PNA) Clamping compared to Direct Sequencing [10], which has a lower sensitivity than the former. The higher increase in EGFR mutation found in this study is attributable to the fact that Direct Sequencing is a very low-sensitive methodology compared to PNA Clamping (10\%-15\% vs. 1\% sensitivity, respectively), whereas we compared Pyrosequencing and MassARRAY ${ }^{\circledR}$ System, which are more similar in terms of sensitivity (5\%-8\% vs. $2 \%-5 \%)$. Taken together, these data suggest that the use of a more sensitive sequencing technique should be recommended in order to also identify patients with a low level of EGFR mutation.

\section{Experimental Section}

\subsection{Case Series}

We conducted a retrospective evaluation of NSCLC EGFR wt patients treated between January 2007 and June 2013 at four institutions in the "Area Vasta Romagna", a geographic area located in the North-East of Italy. EGFR status was determined at diagnosis using histological or cytological specimens and Pyrosequencing methodology, according to the clinical practice. All patients, in order to be eligible for selection, must have had histological specimens for analysis. Patients must have received at least one prior line of chemotherapy. Oral erlotinib was given at a dose of $150 \mathrm{mg} /$ daily on a treatment cycle of 4 weeks. Treatment was continued until disease progression or unacceptable toxicity. Response evaluation was assessed according to Response Evaluation Criteria in Solid Tumor version 1.1 [26]. Patients with partial response or stable disease lasting for at least six months were defined as responsive. Patients with progressive disease or stable disease for less than five months were defined as non-responsive. Clinical data were collected from the databases of our institutions. Patients identified as responsive to erlotinib according to selection criteria were matched for age, gender, smoking status and histotype with an equal number of non-responder patients as a control arm. The study was approved by our Local Ethics Committee.

\subsection{DNA Extraction}

Both cytologic and histologic tumor specimens were accurately selected by qualified pathologists before DNA extraction. For cytologic smears, non-tumor cells were eliminated using a scalpel under an optical microscope while the remaining material, comprising almost $90 \%$ tumor cells, was scraped off the slides and placed in a test-tube. Cells were lysed in $50 \mathrm{mM} \mathrm{KCl}, 10 \mathrm{mM}$ Tris- $\mathrm{HCl} \mathrm{pH}$ 8.0, $2.5 \mathrm{mM}$ $\mathrm{MgCl}_{2}$ and Tween-20 0.45\%, with the addition of Proteinase $\mathrm{K}$ at a concentration of $1.25 \mathrm{mg} / \mathrm{mL}$, 
overnight at $56{ }^{\circ} \mathrm{C}$. Proteinase $\mathrm{K}$ was inactivated at $95{ }^{\circ} \mathrm{C}$ for $10 \mathrm{~min}$ after which samples were centrifuged twice to eliminate debris. Supernatants were assessed for DNA quality and quantity by Nanodrop (Celbio, Milan, Italy) and then underwent PCR amplification.

For paraffin-embedded samples, areas containing at least $70 \%$ of tumor cells were identified on haematoxylin-eosin-stained tissue sections, and $5-\mu \mathrm{M}$ sections of the corresponding areas were macrodissected and collected in specific tubes. DNA extraction was performed as described for cytologic smears.

\subsection{Molecular Determinations}

A panel of 26 genes, for a total of 214 somatic mutations, were analyzed by MassARRAY ${ }^{\circledR}$ System technology (Sequenom, San Diego, CA, USA), using the LungCarta Panel kit (Sequenom, San Diego, CA, USA). Analysis was performed using Typer 4.0 software (Sequenom, San Diego, CA, USA).

\subsection{Statistical Analysis}

Statistical analyses were performed using SPSS software (version 21.0, SPSS Inc, Chicago, IL, USA).

\section{Conclusions}

At present, no conclusion can be drawn in order to select patients sensitive to TKIs in second and further lines of treatment. The results of our study suggest that p53, NOTCH1 and exon 20 EGFR mutations are apparently related to TKI resistance, whereas mutation of PIK3CA, BRAF, STK11, NTRK2 and MET, genes involved in proliferation pathways, were found in responders. KRAS mutations seem not to have a value predictive of response to TKI, although G12C alteration was found more frequently in non-responders. Finally, we confirmed that the use of highly sensitive methodologies could lead to the identification of under-represented EGFR mutations that could be associated with TKI sensitivity. These data need to be confirmed in a wider case series.

\section{Acknowledgments}

We thank Ursula Elbling for editing the manuscript.

\section{Author Contributions}

Paola Ulivi and Claudio Dazzi conceived and designed the study. Paola Ulivi, Elisa Chiadini and Laura Capelli performed the biological determinations. Angelo Delmonte, Maximilian Papi, Marita Mariotti, Alberto Verlicchi, Alessandro Gamboni, Marco Angelo Burgio, Claudia Casanova and Claudio Dazzi provided samples and were responsible for patient follow up. Maurizio Puccetti and Alessandra Dubini revised all histological and cytological samples used for molecular analysis: Angela Ragazzini was the data manager for the study. Paola Ulivi and Angelo Delmonte drafted the manuscript; Daniele Calistri, Claudio Dazzi, Lucio Crinò and Dino Amadori carried out a critical revision of the manuscript for important intellectual content. All authors read and approved the final version of the manuscript. 


\section{Conflicts of Interest}

The authors declare no conflict of interest.

\section{References}

1. Mok, T.S.; Wu, Y.L.; Thongprasert, S.; Yang, C.H.; Chu, D.T.; Saijo, N.; Sunpaweravong, P.; Han, B.; Margono, B.; Ichinose, Y.; et al. Gefitinib or carboplatin-paclitaxel in pulmonary adenocarcinoma. N. Engl. J. Med. 2009, 361, 947-957.

2. Rosell, R.; Carcereny, E.; Gervais, R.; Vergnenegrem, A.; Massuti, B.; Felip, E.; Palmero, R.; Garcia-Gomez, R.; Pallares, C.; Sanchez, J.M.; et al. Spanish Lung Cancer Group in collaboration with Groupe Français de Pneumo-Cancérologie and Associazione Italiana Oncologia Toracica. Erlotinib versus standard chemotherapy as first-line treatment for European patients with advanced EGFR mutation-positive non-small-cell lung cancer (EURTAC): A multicentre, open-label, randomised phase 3 trial. Lancet Oncol. 2012, 13, 239-246.

3. Shepherd, F.A.; Rodrigues Pereira, J.; Ciuleanu, T.; Tan, E.H.; Hirsh, V.; Thongprasert, S.; Campos, D.; Maoleekoonpiroj, S.; Smylie, M.; Martins, R.; et al. National Cancer Institute of Canada Clinical Trials Group. Erlotinib in previously treated non-small-cell lung cancer. N. Engl. J. Med. 2005, 353, 123-132.

4. Kim, E.S.; Hirsh, V.; Mok, T.; Socinski, M.A.; Gervais, R.; Wu, Y.L.; Li, L.Y.; Watkins, C.L.; Sellers, M.V.; Lowe, E.S.; et al. Gefitinib versus docetaxel in previously treated non-small-cell lung cancer (INTEREST): A randomised phase III trial. Lancet 2008, 372, 1809-1818.

5. Gridelli, C.; Ciardiello, F.; Gallo, C.; Feld, R.; Butts, C.; Gebbia, V.; Maione, P.; Morgillo, F.; Genestreti, G.; Favaretto, A.; et al. First-line erlotinib followed by second-line cisplatin-gemcitabine chemotherapy in advanced non-small-cell lung cancer: The TORCH randomized trial. J. Clin. Oncol. 2012, 30, 3002-3011.

6. Garassino, M.C.; Martelli, O.; Broggini, M.; Farina, G.; Veronese, S.; Rulli, E.; Bianchi, F.; Bettini, A.; Longo, F.; Moscetti, L.; et al. TAILOR trialists. Erlotinib versus docetaxel as second-line treatment of patients with advanced non-small-cell lung cancer and wild-type EGFR tumours (TAILOR): A randomised controlled trial. Lancet Oncol. 2013, 14, 981-988.

7. Lee, J.K.; Hahn, S.; Kim, D.W.; Suh, K.J.; Keam, B.; Kim, T.M.; Lee, S.H.; Heo, D.S. Epidermal growth factor receptor tyrosine kinase inhibitors $v s$. conventional chemotherapy in non-small cell lung cancer harboring wild-type epidermal growth factor receptor: A meta-analysis. JAMA 2014, $311,1430-1437$.

8. Zhao, N.; Zhang, X.C.; Yan, H.H.; Yang, J.J.; Wu, Y.L. Efficacy of epidermal growth factor receptor inhibitors versus chemotherapy as second-line treatment in advanced non-small-cell lung cancer with wild-type EGFR: A meta-analysis of randomized controlled clinical trials. Lung Cancer 2014, 85, 66-73.

9. Laurie, S.A.; Goss, G.D. Role of epidermal growth factor receptor inhibitors in epidermal growth factor receptor wild-type non-small-cell lung cancer. J. Clin. Oncol. 2013, 31, 1061-1069. 
10. Han, H.S.; Lim, S.N.; An, J.Y.; Lee, K.M.; Choe, K.H.; Lee, K.H.; Kim, S.T.; Son, S.M.; Choi, S.Y.; Lee, H.C.; et al. Detection of EGFR mutation status in lung adenocarcinoma specimens with different proportions of tumor cells using two methods of differential sensitivity. J. Thorac. Oncol. 2012, 7, 355-364.

11. Zhu, C.Q.; da Cunha Santos, G.; Ding, K.; Sakurada, A.; Cutz, J.C.; Liu, N.; Zhang, T.; Marrano, P.; Whitehead, M.; Squire, J.A.; et al. Role of KRAS and EGFR as biomarkers of response to erlotinib in National Cancer Institute of Canada Clinical Trials Group Study BR.21. J. Clin. Oncol. 2008, 26, 4268-4275.

12. Schneider, C.P.; Heigener, D.; Schott-von-Römer, K.; Gütz, S.; Laack, E.; Digel, W.; Guschall, W.R.; Franke, A.; Bodenstein, H.; Schmidtgen, C.; et al. Epidermal growth factor receptor-related tumor markers and clinical outcomes with erlotinib in non-small cell lung cancer: An analysis of patients from german centers in the TRUST study. J. Thorac. Oncol. 2008, 3, 1446-1453.

13. Eberhard, D.A.; Johnson, B.E.; Amler, L.C.; Goddard, A.D.; Heldens, S.L.; Herbst, R.S.; Ince, W.L.; Jänne, P.A.; Januario, T.; Johnson, D.H.; et al. Mutations in the epidermal growth factor receptor and in KRAS are predictive and prognostic indicators in patients with non-small-cell lung cancer treated with chemotherapy alone and in combination with erlotinib. J. Clin. Oncol. 2005, 23, 5900-5909.

14. Karampeazis, A.; Voutsina, A.; Souglakos, J.; Kentepozidis, N.; Giassas, S.; Christofillakis, C.; Kotsakis, A.; Papakotoulas, P.; Rapti, A.; Agelidou, M.; et al. Pemetrexed versus erlotinib in pretreated patients with advanced non-small cell lung cancer: A Hellenic Oncology Research Group (HORG) randomized phase 3 study. Cancer 2013, 119, 2754-2764.

15. Brugger, W.; Triller, N.; Blasinska-Morawiec, M.; Curescu, S.; Sakalauskas, R.; Manikhas, G.M.; Mazieres, J.; Whittom, R.; Ward, C.; Mayne, K.; et al. Prospective molecular marker analyses of EGFR and KRAS from a randomized, placebo-controlled study of erlotinib maintenance therapy in advanced non-small-cell lung cancer. J. Clin. Oncol. 2011, 29, 4113-4120.

16. Douillard, J.Y.; Shepherd, F.A.; Hirsh, V.; Mok, T.; Socinski, M.A.; Gervais, R.; Liao, M.L.; Bischoff, H.; Reck, M.; Sellers, M.V.; et al. Molecular predictors of outcome with gefitinib and docetaxel in previously treated non-small-cell lung cancer: Data from the randomized phase III INTEREST trial. J. Clin. Oncol. 2010, 28, 744-752.

17. Metro, G.; Chiari, R.; Duranti, S.; Siggillino, A.; Fischer, M.J.; Giannarelli, D.; Ludovini, V.; Bennati, C.; Marcomigni, L.; Baldi, A.; et al. Impact of specific mutant KRAS on clinical outcome of EGFR-TKI-treated advanced non-small cell lung cancer patients with an EGFR wild type genotype. Lung Cancer 2012, 78, 81-86.

18. Fiala, O.; Pesek, M.; Finek, J.; Benesova, L.; Bortlicek, Z.; Minarik, M. Gene mutations in squamous cell NSCLC: Insignificance of EGFR, KRAS and PIK3CA mutations in prediction of EGFR-TKI treatment efficacy. Anticancer Res. 2013, 33, 1705-1711.

19. Niederst, M.J.; Engelman, J.A. Bypass mechanisms of resistance to receptor tyrosine kinase inhibition in lung cancer. Sci. Signal. 2013, 6, doi:10.1126/scisignal.2004652.

20. Cooper, W.A.; Lam, D.C.; O’Toole, S.A.; Minna, J.D. Molecular biology of lung cancer. J. Thorac. Dis. 2013, 5, S479-S490. 
21. Xu, J.; He, J.; Yang, H.; Luo, X.; Liang, Z.; Chen, J.; Cai, Z.; Xu, J.; Ren-Heidenreich, L. Somatic mutation analysis of EGFR, KRAS, BRAF and PIK3CA in 861 patients with non-small cell lung cancer. Cancer Biomark. 2011, 10, 63-69.

22. Chen, D.; Zhang, L.Q.; Huang, J.F.; Liu, K.; Chuai, Z.R.; Yang, Z.; Wang, Y.X.; Shi, D.C.; Liu, Q.; Huang, Q.; et al. BRAF mutations in patients with non-small cell lung cancer: A systematic review and meta-analysis. PLoS One 2014, 9, e101354.

23. Molina-Vila, M.A.; Bertran-Alamillo, J.; Gascó, A.; Mayo-de-Las-Casas, C.; Sánchez-Ronco, M.; Pujantell-Pastor, L.; Bonanno, L.; Favaretto, A.G.; Cardona, A.F.; Vergnenègre, A.; et al. Nondisruptive p53 mutations are associated with shorter survival in patients with advanced non-small cell lung cancer. Clin. Cancer Res. 2014, 20, 4647-4659.

24. Huang, S.; Benavente, S.; Armstrong, E.A.; Li, C.; Wheeler, D.L.; Harari, P.M. p53 modulates acquired resistance to EGFR inhibitors and radiation. Cancer Res. 2011, 71, 7071-7079.

25. Xie, M.; He, C.S.; Wei, S.H.; Zhang, L. Notch-1 contributes to epidermal growth factor receptor tyrosine kinase inhibitor acquired resistance in non-small cell lung cancer in vitro and in vivo. Eur. J. Cancer 2013, 49, 3559-3572.

26. Eisenhauer, E.A.; Therasse, P.; Bogaerts, J.; Schwartz, L.H.; Sargent, D.; Ford, R.; Dancey, J.; Arbuck, S.; Gwyther, S.; Mooney, M.; et al. New response evaluation criteria in solid tumours: Revised RECIST guideline (version 1.1). Eur. J. Cancer 2009, 45, 228-247.

(C) 2014 by the authors; licensee MDPI, Basel, Switzerland. This article is an open access article distributed under the terms and conditions of the Creative Commons Attribution license (http://creativecommons.org/licenses/by/4.0/). 